\title{
PESQUISA QUALITATIVA EM ADMINISTRAÇÃO
}

O desenvolvimento da pesquisa qualitativa está associado às diferentes abordagens teóricas das Ciências Sociais que floresceram ao longo do século XX. Ainda que sob a denominação "pesquisa qualitativa" coexistam diversos sentidos, sua essência está ligada a uma abordagem intepretativista do tema e é, muitas vezes, associada a uma crítica das abordagens positivistas e /ou meramente quantitativas. Pesquisadores que se apóiam em abordagens qualitativas partilham, de modo geral, de uma visão do mundo como uma realidade construída e da existência de uma relação entre o sujeito que pes- quisa e o objeto que é pesquisado. Por outro lado, as abordagens quantitativas enfatizam a mensuração, a neutralidade na relação sujeito-objeto e uma análise causal entre variáveis. Ainda hoje a pesquisa qualitativa é questionada e criticada por não oferecer a objetividade pretendida pela ciência. Apesar disso, a oposição e o estranhamento entre pesquisa qualitativa e quantitativa vêm sendo abandonados e abordagens multimétodos tornam-se cada vez mais freqüentes. Abaixo encontramos algumas obras sobre o tema indicadas pela Professora Maria José Tonelli da FGV-EAESP.
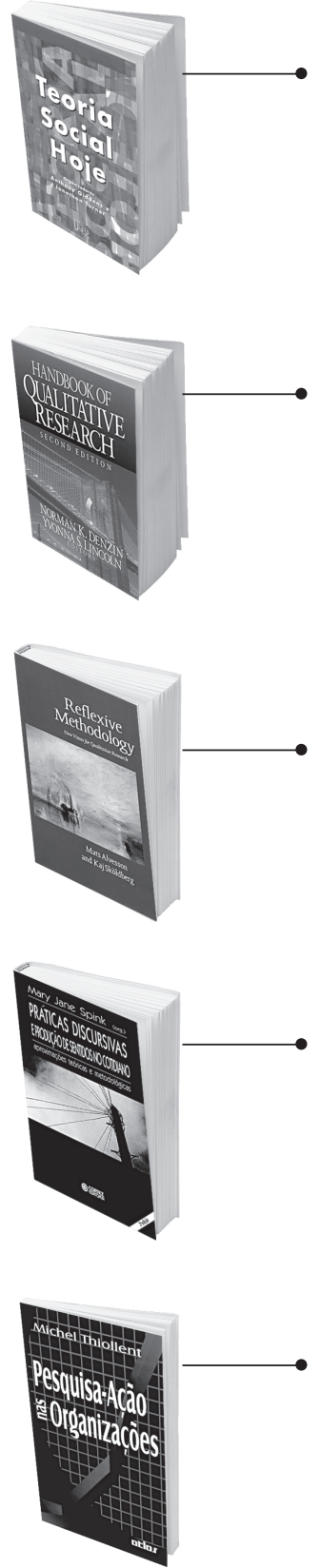

TEORIA SOCIAL HOJE Anthony Giddens e Jonathan Turner (Orgs.). São Paulo: Editora da Unesp, 1999. 609 p. Giddens e Turner partem da idéia de que não há consenso em Teoria Social e que é justamente essa diversidade quando, mapeada, que pode fornecer as bases conceituais e orientar o leitor em sua escolha teórico-metodológica. A coletânea apresenta autores renomados na discussão sobre, entre outros, behaviorismo e pós-behaviorismo, interacionismo simbólico, teoria parsoniana, estruturalismo e pós-estruturalismo, etnometodologia e teoria crítica.

HANDBOOK OF QUALITATIVE RESEARCH Norman Denzin and Yvonna Lincoln (Eds.). Thousand Oaks: Sage, 1994. 643 p. É possível encontrar, nas 643 páginas deste livro, uma vasta discussão sobre diversas abordagens qualitativas. Na primeira parte, vários autores discutem a história, as tradições, as preferências, bem como questões políticas e éticas presentes na pesquisa qualitativa. A segunda parte está dedicada aos principais paradigmas presentes na abordagem qualitativa: construtivismo, teoria crítica, feminismo, modelagem étnica e questões culturais. Na terceira parte, o leitor encontra a discussão de uma série de estratégias de pesquisa: estudo de caso, etnografia, pesquisa clínica, biografias, entre outras. Na quarta parte, são apresentados métodos de coleta de dados e de análise de material empírico, como, por exemplo, técnicas de observação, análise de imagens, e uso de computador em pesquisa qualitativa. Na quinta parte, diversos autores discutem a "a arte da interpretação". E, na última parte, são apresentados alguns questionamentos sobre o futuro da pesquisa qualitativa.

REFLEXIVE METHODOLOGY - new vistas for qualitative research Mats Alvesson and Kaj Skoldberg. London: Sage, 2001.319p.

O livro de Alvesson e Skolberg tem um apelo particular, uma vez que os dois, além de especialistas em métodos qualitativos, são também professores em escolas de Administração. Os autores indicam claramente sua posição: "o conhecimento não pode ser separado do conhecedor" e "dados e fatos são construções ou resultam de interpretação" (p. 1). A partir dessas proposições, os autores discutem, entre outras, hermenêutica, etnometodologia, etnografia, fenomenologia crítica.

\section{PRÁTICAS DISCURSIVAS E PROdUÇÃo DE SENTIDO NO COTIDIANO Mary Jane Spink (Org.). São Paulo: Cortez,} 2000. 296 p.

O livro de Mary Jane e colaboradores é estimulante por vários aspectos: além de apresentar a abordagem teórico-metodológica - apoiada no construcionismo -, também discute vários procedimentos de coleta e análise de dados, em documentos, mídia e entrevistas, de modo que o leitor encontra indicações práticas e rigor metodológico para orientação da pesquisa. Trata-se de uma abordagem em Ciências Humanas ligada à Análise do Discurso e à importância da linguagem não só na construção do conhecimento, mas também nas práticas do cotidiano.

- PESQUISA-AÇÃo NAS ORGANIZAÇõeS Michel Thiollent. São Paulo: Atlas, 1997. 164 p.

Para aqueles que entendem que a ação e a transformação organizacional são fundamentais no trabalho científico, este livro de Thiollent é uma indicação fundamental. É claro que a pesquisa-ação insere-se nas controvérsias que envolvem todo o campo do conhecimento científico: a pesquisa científica deve ser necessariamente aplicada? A pesquisa científica deve ser necessariamente empírica? De acordo com Thiollent, existe na pesquisa-ação "um grande desafio [que] consiste em desenvolver a instrumentalidade sem excluir o 'espírito crítico"' (p. 26). 